(2). $\begin{array}{r}2018 \text { Volume 24(1): 27-47 } \\ \text { ditors }\end{array}$

\title{
DEVELOPMENT OF THE LIFE-CYCLE ECONOMIC AND ENVIRONMENTAL ASSESSMENT MODEL FOR ESTABLISHING THE OPTIMAL IMPLEMENTATION STRATEGY OF THE ROOFTOP PHOTOVOLTAIC SYSTEM
}

\author{
Choongwan KOO ${ }^{\mathrm{a}, \mathrm{b}}$, Taehoon $\mathrm{HONG}^{\mathrm{b}}$, Joonho PARK \\ ${ }^{a}$ Divison of Construction Engineering and Management, Purdue University, \\ West Lafayette, IN 47906, USA \\ ${ }^{b}$ Department of Architectural Engineering, Yonsei University, 03722, Seoul, Republic of Korea \\ ${ }^{c}$ Department of Industrial \& Logistics, CBRE Korea, 110-702, Seoul, Republic of Korea
}

Received 27 October 2014; accepted 16 May 2015

\begin{abstract}
To maximize the life-cycle economic and environmental performance of the rooftop photovoltaic (PV) system in real projects, it is necessary to consider several factors such as regional climate factors (i.e., geographical and meteorological factors) and building characteristics (i.e., onsite installation factors, rooftop area limit, and budget limit). Towards this end, this study aimed to develop the life-cycle economic and environmental assessment model for establishing the optimal implementation strategy of the rooftop PV system. The robustness and reliability of the developed model were evaluated in terms of two perspectives: (i) for the effectiveness of the optimal solution, the optimization results were generated by considering the regional climate factors and building characteristics. Namely, the results for $\operatorname{SIR}_{25}$ (saving to investment ratio at year 25), which was set at the optimization goal, were 2.540 (Busan, southern part of South Korea), 2.485 (Daejeon, central part of South Korea), and 2.266 (Seoul, northern part of South Korea), respectively; and (ii) for the efficient computation time, the time required for determining the optimal solution was only 27 seconds. The developed model can be used to easily and accurately assess the life-cycle economic and environmental performance of the rooftop PV system in the early design phase.
\end{abstract}

Keywords: rooftop photovoltaic system, economic and environmental assessment, forecasting and simulation, optimization, sustainable development, life cycle cost analysis.

JEL Classification: C52, C61, C63, D81, E27, L74, Q01, Q21, R47.

Online supplementary material: Supporting information for this paper is available as online supplementary material at: http://dx.doi.org/10.3846/20294913.2015.1074127

Corresponding author Taehoon Hong

E-mail:hong7@yonsei.ac.kr 


\section{Introduction}

The rapid increase in the use of fossil fuels caused the energy depletion and environmental pollution. Despite the various efforts for carbon emissions reduction around the world, global energy consumption continues to rise. World primary energy consumption in 2010 was increased by $5.6 \%$, the highest rate since 1973. Among these, primary energy consumption of OECD countries has also soared to 3.5\%, the highest rate since 1984, and that of non-OECD countries has doubled to 7.5\% (DOS 2010; EEA 2011; Hong et al. 2014a; IPCC 2007; UN 1998). According to the "2010 Survey of Energy Resources" of the World Energy Council, the reserves-to-production ratios of coal, natural gas, and oil are believed to be 128 years, 54 years, and 41 years, respectively. It is projected that all fossil fuels may be used up within 50 years (IEA 2010; KEA 2000; WEC 2010). Accordingly, leading countries are establishing more renewable energy power plants. As of 2009, electricity generation using renewable energy was about 18\% of global electricity generation (IEA 2008a; JRC 2011). According to a press release, renewable energy power plants accounted for more than $50 \%$ of newly installed power plants in the EU and the U.S. (IEA 2008b; MEI 2011).

Keeping in pace with the global trend, South Korea has established its third master plan for new renewable energy generation and has set up its mid- to long-term goals. It recently founded the New and Renewable Energy Center under the Korea Energy Management Corporation (KEMCO) and is promoting various policies such as 1 Million Green Homes Project and Renewable Portfolio Standard (Hong et al. 2014b, 2013; MKE 2011). Especially, it is considered that the photovoltaic (PV) system, among the various types of new renewable energy, has great potential as a sustainable clean energy source. The continuous downward trend in the cost of the PV system is steadily boosting the installation of the PV system. Despite the decrease in their cost, however, they still have a high initial investment cost (IIC). Accordingly, it is required to analyze the life-cycle economic and environmental performance of the rooftop PV system before implementing it to the existing buildings in real projects (IRENA 2012; KMCCA 2011; Koo et al. 2013).

Therefore, this study aimed to develop the life-cycle economic and environmental asf sessment model for establishing the optimal implementation strategy of the rooftop PV system. The developed model could help final decision-makers (such as an architect, a construction manager, and a contractor) to assess the life-cycle economic and environmental performance of the rooftop PV system in the early design phase and to analyze the return on investment in a competitive bidding process. This study was conducted in three steps: (i) step 1: definition of the impact factors of the rooftop PV system through an extensive literature review and interviews with experts in the field of the PV system; (ii) step 2: sensitivity analysis on the impact factors of the rooftop PV system in terms of two aspects (i.e., unit panel and rooftop PV system); and (iii) step 3: development of the life-cycle economic and environmental assessment model for the rooftop PV system by considering various processes and the associated equations using a Microsoft-Excel-based VBA (refer to Supporting Information (SI) Figure S1).

Meanwhile, this study has established the 15 scenarios to verify the applicability of the developed model. First, this study selected three representative regions (i.e., Seoul, Daejeon, 
and Busan, which are located in the northern, central, and southern parts of South Korea, respectively) by considering the regional climate factors such as the geographical factors and the meteorological factors. Second, this study established five types of buildings by considering the building characteristics (i.e., rooftop shape and rooftop area). As a result, this study established a total of $15(3 \times 5)$ scenarios by considering three representative regions and five types of buildings. Finally, this study has evaluated the robustness and relif ability of the developed model in terms of two criteria: (i) consideration of the effectiveness of the optimal solution; and (ii) coming up with an efficient computation time.

\section{Literature review}

As shown in Table 1, this study has reviewed several previous studies on the various impact factors affecting the electricity generation performance of the rooftop PV system. Through the extensive literature review, this study has largely categorized the impact factors of the rooftop PV system into two parts: (i) the regional climate factors (i.e., geographical factors and meteorological factors) and (ii) the building characteristics (i.e., on-site installation factors, rooftop area limit, and budget limit).

Several previous studies have been conducted using diverse approaches. First, some studies have focused on two or less impact factors for maximizing the electricity generation performance of the rooftop PV system. Bojić et al. (2012) has analyzed how the SoP afS fects the electricity generation performance of the rooftop PV system. Braun et al. (2013), Dincer, Meral (2010), and Hoffmann, Koehl (2014) have analyzed how the monthly average temperature affects the electricity generation performance of the solar cells in the PV panels. Badescu (2006) has simultaneously analyzed the latitude and the ToP as the impact factors of the rooftop PV system, Levinson et al. (2009) has considered the latitude and the azimuth of the installed panel (AoP) at the same time, and Tiris, M., Tiris, C. (1998) have considered the latitude and the slope of the installed panel (SoP) at once. Sarhaddi et al. (2009) aimed to maximize the electricity generation performance of the rooftop PV system by considering the monthly average temperature and rooftop area limit.

Second, other studies have examined the ways of maximizing the electricity generation performance of the rooftop PV system by considering three or more categories for the impact factors of the rooftop PV system. Siraki, Pillay (2012) has analyzed the optimal AoP and SoP with the consideration of the latitude and the monthly average daily solar radiation (MADSR) in order to maximize the electricity generation performance of the rooftop PV system. Weinstock, Appelbaum (2009) have analyzed the optimal AoP and SoP for maximizing the electricity generation performance of the rooftop PV system within the maximum width and length limit. Zhao et al. (2010) aimed to determine the optimal SoP by considering the latitude and the monthly meridian altitude depending on the installation location. Gong, Kulkarni (2005) has analyzed the optimal AoP and SoP for maximizing the electricity generation performance of the rooftop PV system within the maximum width and length limit under the maximum budget limit.

Meanwhile, Hong et al. (2014c) conducted a sensitivity analysis on the impact factors of the rooftop PV system (i.e., regional climate factors, AoP, and SoP) that can affect annual 
electricity generation (AEG) performance in terms of the unit panel of the rooftop PV system. This study has resulted in the following three major conclusions: (i) the 1.12-fold difference in the AEG has occurred depending on the regional climate factors such as the geographic and meteorological factors; (ii) the 1.62-fold difference in the AEG has occurred depending on the AoP; and (iii) the 1.37-fold difference in the AEG has occurred depending on the SoP. Likewise, Hong et al. (2014c) has focused on the unit panel of the rooftop PV system as a preliminary study. For the actual project, however, the additional

Table 1. Reviews on the impact factors affecting the electricity generation performance of the rooftop PV system

\begin{tabular}{|c|c|c|c|c|}
\hline \multicolumn{3}{|c|}{ Impact factors } & \multirow{2}{*}{$\frac{\text { Unit }}{()^{\circ} \mathrm{N}}$} & \multirow[b]{2}{*}{\begin{tabular}{l}
\multicolumn{1}{c}{ Reference } \\
Badescu (2006), Hong et al. \\
(2014c), Levinson et al. (2009), \\
Siraki, Pillay (2012), Tiris, M., \\
Tiris, C. (1998), Weinstock, \\
Appelbaum (2009), Zhao et al. \\
(2010).
\end{tabular}} \\
\hline $\begin{array}{l}\text { Regional } \\
\text { climate } \\
\text { factors }\end{array}$ & $\begin{array}{l}\text { Geographical } \\
\text { factors }\end{array}$ & Latitude & & \\
\hline & & $\begin{array}{l}\text { Monthly } \\
\text { meridian } \\
\text { altitude }\end{array}$ & ()$^{\circ}$ & $\begin{array}{l}\text { Hong et al. (2014c), Kaldellis, } \\
\text { Zafirakis (2012), Zhao et al. } \\
\text { (2010). }\end{array}$ \\
\hline & $\begin{array}{l}\text { Meteorological } \\
\text { factors }\end{array}$ & $\begin{array}{l}\text { Monthly } \\
\text { average daily } \\
\text { solar radiation } \\
\text { (MADSR) }\end{array}$ & ( ) $\mathrm{kWh} / \mathrm{m}^{2} /$ day & $\begin{array}{l}\text { Hong et al. (2014c), Kaldellis, } \\
\text { Zafirakis (2012), } \\
\text { Siraki, Pillay (2012). }\end{array}$ \\
\hline & & $\begin{array}{l}\text { Monthly average } \\
\text { temperature }\end{array}$ & ()$^{\circ} \mathrm{C}$ & $\begin{array}{l}\text { Braun et al. (2013), Dincer, Meral } \\
\text { (2010), Hoffmann, Koehl (2014), } \\
\text { Hong et al. (2014c), } \\
\text { Sarhaddi et al. (2009). }\end{array}$ \\
\hline \multirow[t]{5}{*}{$\begin{array}{l}\text { Building } \\
\text { character- } \\
\text { istics }\end{array}$} & $\begin{array}{l}\text { On-site } \\
\text { installation } \\
\text { factors }\end{array}$ & $\begin{array}{l}\text { The azimuth } \\
\text { of the installed } \\
\text { panel (AoP) }\end{array}$ & ()$^{\circ}$ & $\begin{array}{l}\text { Gong, Kulkarni (2005), Hong } \\
\text { et al. (2014c), Kaldellis, Zafirakis } \\
\text { (2012), Levinson } \text { et al. (2009), } \\
\text { Siraki, Pillay (2012), Weinstock, } \\
\text { Appelbaum (2009). }\end{array}$ \\
\hline & & $\begin{array}{l}\text { The slope of the } \\
\text { installed panel } \\
(\mathrm{SoP})\end{array}$ & ()$^{\circ}$ & $\begin{array}{l}\text { Bojić et al. (2012), Gong, Kulkarni } \\
\text { (2005), Hong et al. (2014b), Hong } \\
\text { et al. (2014c), Hong et al. (2013), } \\
\text { Kaldellis, Zafirakis (2012), Siraki, } \\
\text { Pillay (2012), Tiris, M., Tiris, C. } \\
\text { (1998), Weinstock, Appelbaum } \\
\text { (2009), Zhao et al. (2010). }\end{array}$ \\
\hline & & $\begin{array}{l}\text { The type of the } \\
\text { panel (ToP) and } \\
\text { inverter (ToI) }\end{array}$ & ( ) & $\begin{array}{l}\text { Badescu (2006), Gong, Kulkarni } \\
\text { (2005), Ordonez et al. (2010). }\end{array}$ \\
\hline & $\begin{array}{l}\text { Rooftop area } \\
\text { limit }\end{array}$ & $\begin{array}{l}\text { Maximum } \\
\text { width limit } \\
\text { and maximum } \\
\text { length limit }\end{array}$ & ( ) $\mathrm{m}$ & $\begin{array}{l}\text { Gong, Kulkarni (2005), Sarhaddi } \\
\text { et al. (2009), } \\
\text { Weinstock, Appelbaum (2009). }\end{array}$ \\
\hline & Budget limit & $\begin{array}{l}\text { Maximum } \\
\text { budget limit }\end{array}$ & US\$ ( ) & $\begin{array}{l}\text { Gong, Kulkarni (2005), Harder, } \\
\text { Gibson (2011). }\end{array}$ \\
\hline
\end{tabular}


constraints such as the rooftop area limit of a given building and the maximum budget limit should be simultaneously considered to determine the optimal implementation strategy of the rooftop PV system.

As mentioned above, it is significant that the previous studies have been conducted to investigate the various impact factors which can affect the electricity generation performance of the rooftop PV system. Also, some of the previous studies have systematically conducted sensitivity analyses on these impact factors in terms of the unit panel of the rooftop PV system. However, the previous studies have overlooked the critical factors that should be considered in implementing the rooftop PV system to the existing buildings in real projects as follows.

- It is necessary to conduct the sensitivity analysis on the impact factors in terms of the rooftop PV system by considering the optimization goal such as net present value (NPV) and saving-to-investment ratio (SIR) and the constraint parameters such as rooftop area limit and budget limit.

- It is required to analyze the life-cycle economic and environmental performance for establishing the optimal implementation strategy of the rooftop PV system.

- It is important to develop the decision support model that can help final decisionmakers (such as policymakers, construction managers, and contractors) to assess the life-cycle economic and environmental performance of the rooftop PV system simply by entering the optimization parameters in the early design phase and the competitive bidding process of real projects.

Therefore, this study was designed to fill the knowledge gap. First, this study systematid cally conducted the sensitivity analysis on the impact factors in terms of the rooftop PV system. Next, this study developed the life-cycle economic and environmental assessment model by considering the sensitivity analysis and the optimization parameters.

\section{Materials and methods}

\subsection{Step 1: Definition of the impact factors of the rooftop PV system}

To maximize the effect of the rooftop PV system in real projects, several factors should be considered. The following impact factors of the rooftop PV system were established based on extensive literature review and interviews with experts in the field of the PV system (i.e., Parsons Brinckerhoff, Oerlikon Solar, and Hilti Corporation): (i) regional geographical information; (ii) regional meteorological information; (iii) on-site installation information; (iv) the rooftop factor; and (v) the budget limit (refer to Table 1).

- Regional geographical information: This factor can be divided into the latitude and the monthly meridian altitude. The latitudes in 78 regions were collected from the geographical information offered by Google Earth ${ }^{\mathrm{TM}}$.

- Regional meteorological information: This factor can be divided into the MADSR and the monthly average temperature. First, Koo et al. (2013) developed an Advanced Case-Based Reasoning (A-CBR) for estimating the MADSR using the monthly geographic and meteorological data measured in 15 regions for 10 years. Also, Lee et al. (2014) estimated the MADSR at the 54 unmeasured locations in South Korea 
using the A-CBR developed by Koo et al. (2013). As a result, the MADSR data in 78 regions, which consists of 24 locations with the measured MADSR data and 54 locations with the estimated MADSR data, were used in this study (refer to SI Tables S1 and S2 and SI Figure S2). For detailed information on the algorithms for the A-CBR model, refer to the Koo et al. (2013). Second, using the meteorological data in 78 weather stations nationwide measured by the Korea Meteorological Administration, the monthly average temperature was collected.

- On-site installation information: This factor can be divided into the AoP, the SoP, and the type of the panel (ToP) and inverter (ToI). First, the AEG are highest when the AoP is $0^{\circ}$ (southward) regardless of the region. Thus, the unit panels of the rooftop $\mathrm{PV}$ system are generally installed toward the south (orientation $=0^{\circ}$ ). Second, the AEG is highest when the incidence angle of the sun is perpendicular to the unit panels of the rooftop PV system. Accordingly, the unit panels of the rooftop PV system are generally installed by considering the monthly meridian altitude of a given region in order to maximize the return on investment of the rooftop PV system. Third, there are various characteristics of the unit panels of the rooftop PV system such as power capacity, efficiency, miscellaneous, width and length, and unit cost. Thus, the ToP should be determined by considering the building characteristics such as the rooftop area limit and budget limit.

- Rooftop factor: The number of the installed panels (NoP), which can be installed on the rooftop PV system, depends on the rooftop factor of the target building. Namely, the installed length of the panel (ILP) depends on the meridian altitude at noon of the winter solstice, the SoP, and the ToP (refer to SI Figure S3 and Eq. (1)). Consequently, the number of the panels, which can be installed on the rooftop PV system, changes (refer to Eq. (2)). That is, the NoP along the length of the rooftop area (NoP_L) can be calculated by dividing the length of the rooftop area $\left(\mathrm{L}_{\mathrm{rt}}\right)$ by the ILP. In addition, the NoP along the width of the rooftop area (NoP_W) can be calculated by dividing the width of the rooftop area $\left(\mathrm{W}_{\mathrm{rt}}\right)$ by the width of the panel $\left(\mathrm{W}_{\mathrm{p}}\right)$.

- Budget limit: Based on the life-cycle economic and environmental assessment of the rooftop PV system, the optimal scenario should be determined within the maximum budget limit in order to maximize the return on investment of the rooftop PV system.

$$
\begin{aligned}
I L P & =\left(I L P_{b}+I L P_{s}\right)=L_{p} \times\left(\cos \beta+\frac{\sin \beta}{\tan \tau}\right) ; \\
N o P & =N o P_{-} L \times N o P_{-} W=\left(\frac{L_{r t}}{I L P}\right) \times\left(\frac{W_{r t}}{W_{p}}\right),
\end{aligned}
$$

where: ILP stands for the installed length of the panel; $I L P_{b}$, for the base length of the installed panel; $I L P_{s}$, for the shadow length of the installed panel; $L_{p}$, for the length of the panel; $\beta$, for the installed angle of the panel; $\tau$, for the meridian altitude at noon of the winter solstice (= 90 - latitude - 23.5); NoP_L, for the number of the installed panels along the length of the rooftop area; $L_{r t}$, for the length of the rooftop area; NoP_W, for the number of the installed panels along the width of the rooftop area; $W_{r t}$, for the width of the rooftop area; $W_{p}$, for the width of the panel; and NoP, for the number of the installed panels. 


\subsection{Step 2: Sensitivity analysis on the impact factors of the rooftop PV system}

This study conducted the sensitivity analysis on the impact factors affecting the life-cycle economic and environmental performance of the rooftop PV system. In terms of the unit panel, this study analyzed the relationship between the annual electricity generation per unit panel (AEG/unit) and the ILP by considering the change of the SoP. In terms of the rooftop PV system, this study conducted the sensitivity analysis on the life-cycle economic and environmental performance of the rooftop PV system by considering the change of the SoP.

Meanwhile, the software program "RETScreen" has been actively used to calculate the AEG of the rooftop PV system. The software program "RETScreen" was developed by specialists from the Department of Natural Resources in Canada and the United Nations Environment Programme (MNR 2010). As of 2010, more than 20,000 copies have been downloaded worldwide. The simulated energy generation using "RETScreen" showed an error below 6\%, compared to the actual energy generation. Therefore, the software proe gram "RETScreen" is considered an excellent one for evaluating the electricity generation performance of the rooftop PV system (Hong et al. 2014c; Koo et al. 2013).

\subsection{Step 3: Development of the life-cycle economic and environmental assessment model}

\subsubsection{Considerations for systemization}

In implementing the rooftop PV system for the target building, the final decision-makers should consider various processes and the associated equations to find the optimal solution of the rooftop PV system. Also, several impact factors, which can affect the life-cycle economic and environmental performance of the rooftop PV system, should be considered. Thus, the several impact factors should be integrated into a system, and the optimization process should be applied to the system. This study used a Microsoft-Excel-based VBA for developing the life-cycle economic and environmental assessment model for the rooftop PV system (refer to Figures 1 and 2). The following considerations were taken into account in developing the model. In this system, the regional information and the PV panel's information, which can affect the electricity generation performance of the rooftop PV system, can be updated consistently.

- Part (A), Optimization Goal: According to the project goals of the final decisionmakers and the project characteristics, the optimization goal (i.e., the NPV or the SIR) can be selected (refer to Part (A) of Figure 1).

- Part (B), Defined Parameters: The final decision-makers can determine the region and the azimuth of the target building by considering the location where the rooftop PV system would be installed (refer to Part (B) of Figure 1).

- Part (C), Adjustable Parameters: The ToP and the SoP can be determined by considering the optimization goal and the constraints such as rooftop area limit and budget limit. And then, the NoP and the AEG can be calculated. These results can affect the life-cycle economic and environmental performance of the rooftop PV system (refer to Part (C) of Figure 1). 
- Part (D), Constraint Parameters: The final decision-makers can establish the constraint parameters such as the rooftop shape and the maximum rooftop area limit of the target building and the maximum budget limit by considering the project characteristics (refer to Part (D) of Figure 1).

Meanwhile, as shown in SI Table S3, this study has established the key elements for conducting the LCC and $\mathrm{LCCO}_{2}$ analyses as follows (Dell'Isola, Kirk 2003).

- (i) Analysis approach: This study used the present worth method, which can be expressed largely as two indices: the NPV as an absolute index (Eq. (3)) and the SIR as a relative index (Eq. (4)).

- (ii) Real discount rate: Using the basic information from the Bank of Korea Economic Statistics (ECOS) system and the Korean Statistical Information Service (KOSIS), the real discount rate was calculated: the interest growth rate $(3.30 \%)$; the electricity price growth rate $(0.66 \%)$; and the carbon dioxide emission trading price growth rate (2.66\%) (ECOS 2013; KOSIS 2013).

- (iii) Analysis period: The useful life of the PV panel was set at 25 years by considering the warranty period of the PV panel established by manufacturers (Brearley 2009).

- (iv) Significant cost of ownership: The significant cost of ownership was established by considering the IIC, the initial benefit, the operation and maintenance cost, and the operation and maintenance benefit. Based on market research, this study established the IIC (US $\$ 1,410 / \mathrm{kW}$ ) and the repair rate ( $1 \%$ of the IIC/yr.) of the unit panel (CAK 2012). In addition, based on the basic information from the New and Renewable Energy Centre (NREC), this study established the government subsidy (40\% of the IIC) as the initial benefit (NREC 2013). In particular, the operation and maintenance benefits included the benefit from energy savings and the benefit from the sale of carbon credits (US\$11.12/ $\mathrm{tCO}_{2}$ ), called "Korea Certified Emission Reductions (KCERs)" (KEMCO 2013a).

\begin{tabular}{|c|c|c|c|c|}
\hline \multirow[t]{2}{*}{ Genetic Algorithm } & \multicolumn{4}{|c|}{$\begin{array}{l}\text { Life-Cycle Economic and Environmental Assessment Model } \\
\text { for Establishing the Optimal Implementation Strategy of the Rooftop Photovoltaic System }\end{array}$} \\
\hline & Classification & Value & Note & \\
\hline \multirow{4}{*}{$\begin{array}{l}\text { (A) } \\
\text { Optimization Goal } \\
\text { (Opt. G) }\end{array}$} & $\begin{array}{l}\text { IIC: Initial Investment Cost (US\$) } \\
\end{array}$ & 103,280 & Minimization & 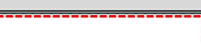 \\
\hline & $\square$ AEG: Annual Electricity Generation & 160,030 & Maximization & \\
\hline & $\square \quad$ NPV25: Net Present Value & 249,213 & Maximization & \\
\hline & V SIR25: Saving-to-Investment Ratio & 2.266 & Maximization & \\
\hline \multirow{4}{*}{$\begin{array}{l}\text { (B) } \\
\text { Defined Parameters } \\
\text { (C) } \\
\text { Adjustable Parameters }\end{array}$} & Region (Seoul) & 1 & $\overline{1}$ & 16 \\
\hline & AoP: Aximuth of the installed Panel $\left({ }^{\circ}\right)$ & $0^{\circ}$ & $0^{\circ}$ & $90^{\circ}$ \\
\hline & ToP: Type of the Panel & 30 & 1 & 49 \\
\hline & SoP: Slope of the installed Panel $\left({ }^{\circ}\right)$ & $36^{\circ}$ & $0^{\circ}$ & $90^{\circ}$ \\
\hline \multirow{5}{*}{ Constraint Parameter } & NoP_L: Number of Panels (Length) (EA) & $14 \mathrm{EA}$ & Installed Length of the Panel (ILP) (m) & $2.75 \mathrm{~m}$ \\
\hline & NoP_W: Number of Panels (Width) (EA) & $40 \mathrm{EA}$ & Width per unit panel (Wp) (m) & $0.98 \mathrm{~m}$ \\
\hline & Applied Length (m) & $38.45 \mathrm{~m}$ & Rooftop Length Limit (m) & $40.0 \mathrm{~m}$ \\
\hline & Applied Width (m) & $39.32 \mathrm{~m}$ & Rooftop Width Limit (m) & $40.0 \mathrm{~m}$ \\
\hline & Construction Cost (USS) & 172,133 & Budget Limit (USS) & 125,000 \\
\hline
\end{tabular}

Fig. 1. Graphical user interface of the proposed model 


\section{Life-Cycle Economic and Environmental Assessment Model for Establishing the Optimal Implementation Strategy of the Rooftop Photovoltaic System}

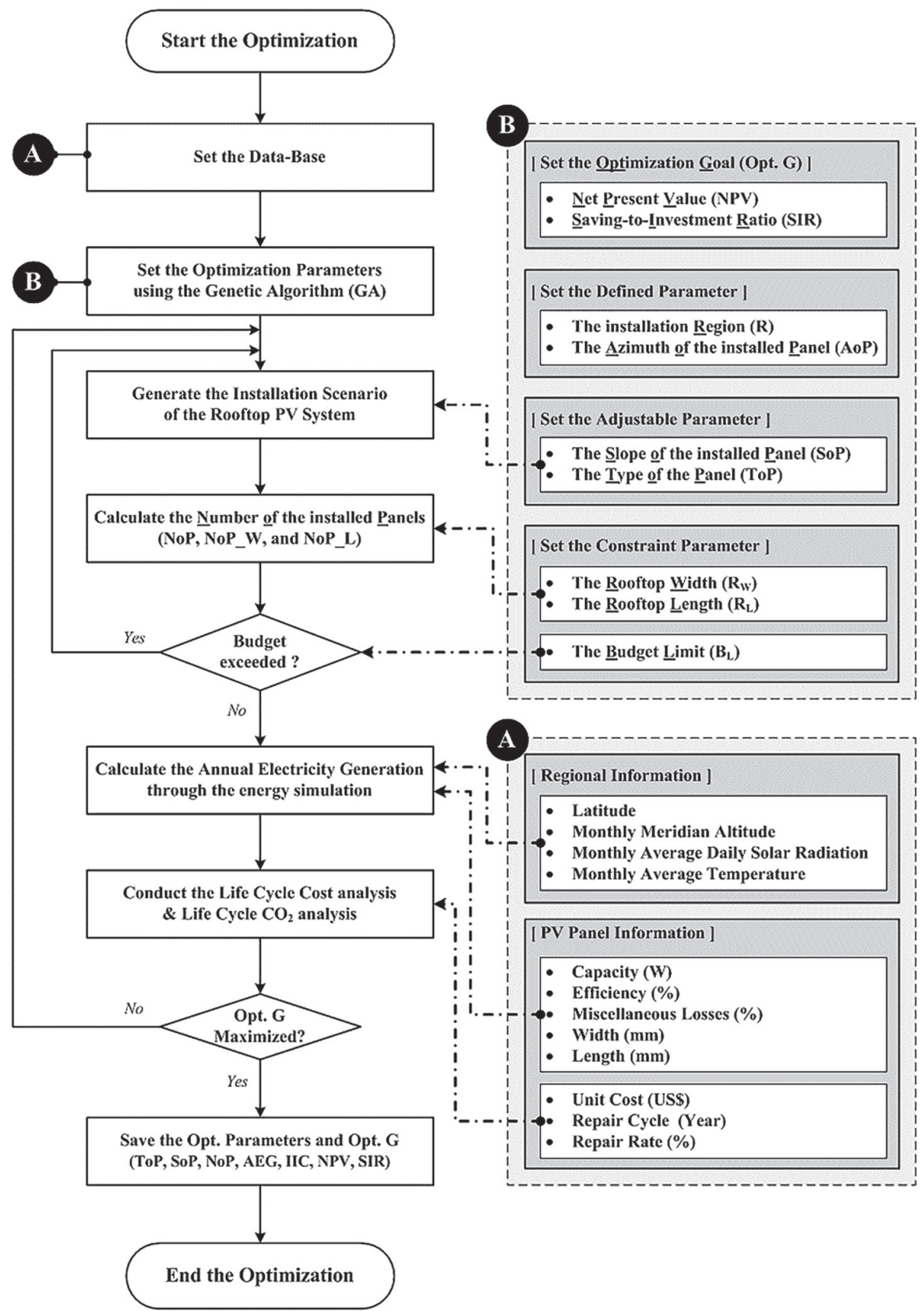

Fig. 2. Development process of the proposed model 


$$
\begin{aligned}
& N P V_{n}=\sum_{t=0}^{n} \frac{B E G_{t}+B E T_{t}}{(1+r)^{t}}-\sum_{t=0}^{n} \frac{C I_{t}+C R_{t}}{(1+r)^{t}} ; \\
& S I R_{n}=\sum_{t=0}^{n} \frac{B E G_{t}+B E T_{t}}{(1+i)^{t}} / \sum_{t=0}^{n} \frac{C I_{t}+C R_{t}}{(1+i)^{t}},
\end{aligned}
$$

where: $N P V_{n}$ stands for the net present value during $n$ years; $S I R_{n}$ stands for the savings-toinvestment ratio during $n$ years; $B E G_{t}$ stands for the benefit from the electricity generation in year $t ; B E T_{t}$ stands for the benefit from the emission trading in year $t ; C I_{t}$ stands for the cost of the initial investment in year $t$; $C R_{t}$ stands for the cost of the repair work in year $t$; $i$ stands for the real discount rate; and $n$ stands for the period of the life cycle cost (LCC) and life cycle $\mathrm{CO}_{2}\left(\mathrm{LCCO}_{2}\right)$ analyses.

\subsubsection{Optimization parameters in a genetic algorithm}

In implementing the rooftop PV system to a given building, the optimization process should be established to find the optimal solution. Thus, this study used a genetic algorithm (GA), resulting in that the optimal solution can be determined by considering the optimization parameters such as the optimization goal, defined parameters, adjustable parameters, and constraint parameters. First, this study has defined the SIR (which is generally used as a relative index for evaluating the life-cycle economic and environmental performance of the rooftop PV system) as the optimization goal (i.e., the fitness function). Second, this study has defined the regional climate factors (i.e., the geographical factors and the meteorological factors) and the AoP as the defined parameters. If the final decision-makers select one of the 16 administrative divisions in South Korea, the geographical factors (i.e., the latitude and the monthly meridian altitude) and the meteorological factors (i.e., the MADSR and the monthly average temperature) can be retrieved from the data-base (refer to SI Tables S4 to S6), and then these regional climate factors can be used to evaluate the electricity generation performance of the rooftop PV system. Third, this study has defined a group of optimization parameters as a chromosome, and each of the optimization parameters is defined as a gene (Bhatti 2000; Gen, Cheng 2000; Hong et al. 2014a, 2014c; Koo et al. 2014, 2013). As shown in SI Figure S4, this study defined the chromosome using two adjustable parameters (i.e., the ToP and the SoP) and three constraint parameters (i.e., the rooftop width limit, the rooftop length limit, and the budget limit). By considering the three constraint parameters, the applicable scenarios can be sorted out from all the probable scenarios in advance.

\section{Model application}

To verify the applicability of the developed model, possible scenarios were established for model application by considering the regional climate factors and building characteristics. First, in terms of the regional climate factors, three representative regions were selected based on the latitude. Namely, Seoul, Daejeon, and Busan were selected, which are in the northern, central, and southern parts of South Korea, respectively. The geographical factors 
(i.e., the latitude and the monthly meridian altitude) and the meteorological factors (i.e., the MADSR and the monthly average temperature) of each region are shown in SI Tables S4 to S6. Second, in terms of the building characteristics, the five types were established by considering the rooftop shape and the rooftop area of the target building. The detailed information on the total of 15 scenarios is shown in Table 2. For model application, the following assumptions were established.

- Type of building: The Mandatory Renewable Energy Installation Program is the compulsory regulation enforced by the Ministry of Trade, Industry and Energy in South Korea (KEMCO 2013b). An elementary school included in this program was selected for model application.

- Regional factors: Three representative regions were selected based on the latitude. Namely, Seoul, Daejeon, and Busan were selected, which are in the northern, central, and southern parts of South Korea, respectively (refer to SI Tables S4 to S6). Especially, Seoul, the capital of South Korea and the region with the highest electricity consumption per rooftop area of elementary school facilities $\left(213.376 \mathrm{kWh} / \mathrm{m}^{2}\right)$, was used for the sensitivity analysis (Koo et al. 2014).

- AoP: The unit panel of the rooftop PV system is generally installed toward the south (orientation $=0^{\circ}$ ). Thus, a building that was facing south (orientation $=0^{\circ}$ ) was chosen as the target building.

- SoP: Model application was conducted based on the SoP, which was divided by $1^{\circ}$ in the range from $0^{\circ}$ to $90^{\circ}$. Especially, the sensitivity analysis was conducted based on the SoP, which was divided by $5^{\circ}$ in the range from $0^{\circ}$ to $90^{\circ}$.

- ToP: Through interviews with experts in the field of the PV system (i.e., Parsons Brinckerhoff, Oerlikon Solar, and Hilti Corporation) and market research, the basic information on a total of 49 types of panels was established in the database (refer to SI Table S7). The database was used to conduct the optimization process.

- Rooftop factors: Considering the rooftop shape and the rooftop area of the target building, five types were established (refer to Table 2). Especially, as the average rooftop area of elementary school facilities in Seoul (the target region) is $1,510.4 \mathrm{~m}^{2}$ (Koo et al. 2014), the type of rooftop was set as " $40 \times 40$ square (width $(m) \times l e n g t h(m)$ )" for the sensitivity analysis.

- Budget limit: The constraint of the budget was set at US\$125,000 to clearly present the results of the sensitivity analysis. However, it was assumed that the budget constraints would not be applied for model application. In other words, it was assumed that the maximum number of panels, which can be installed on the rooftop area of the target building, would be applied to model application.

Finally, to evaluate the robustness and reliability of the developed model, this study has established the following two criteria: (i) consideration of the effectiveness of the optimal solution, and (ii) coming up with an efficient computation time. 
Table 2. Scenarios for model application

\begin{tabular}{|c|c|c|c|c|c|}
\hline \multirow[b]{2}{*}{ Scenarios } & \multicolumn{2}{|c|}{ Regional climate factors } & \multicolumn{3}{|c|}{ Building characteristics } \\
\hline & Mark & $\begin{array}{l}\text { Region } \\
\text { (latitude) }\end{array}$ & Mark & $\begin{array}{c}\text { Rooftop shape } \\
\text { (width }(\mathrm{m}) \times \text { length }(\mathrm{m}) \text { ) }\end{array}$ & $\begin{array}{l}\text { Rooftop area } \\
\left(\mathrm{m}^{2}\right)\end{array}$ \\
\hline$\# 1(\mathrm{~S} 1)$ & \multirow{5}{*}{ S } & \multirow{5}{*}{$\begin{array}{l}\text { Seoul, } \\
\text { northern part } \\
\left(37.30^{\circ}\right)\end{array}$} & S1 & $40 \times 40$ & 1.600 \\
\hline$\# 2(\mathrm{~S} 2)$ & & & S2 & $80 \times 20$ & 1.600 \\
\hline$\# 3(\mathrm{~S} 3)$ & & & S3 & $20 \times 80$ & 1.600 \\
\hline$\# 4(\mathrm{~S} 4)$ & & & S4 & $40 \times 20$ & 800 \\
\hline \#5 (S5) & & & S5 & $20 \times 40$ & 800 \\
\hline$\# 6$ (D1) & \multirow{5}{*}{$\mathrm{D}$} & \multirow{5}{*}{$\begin{array}{l}\text { Daejeon, } \\
\text { central part } \\
\left(36.22^{\circ}\right)\end{array}$} & D1 & $40 \times 40$ & 1.600 \\
\hline$\# 7$ (D2) & & & D2 & $80 \times 20$ & 1.600 \\
\hline$\# 8$ (D3) & & & D3 & $20 \times 80$ & 1.600 \\
\hline$\# 9$ (D4) & & & D4 & $40 \times 20$ & 800 \\
\hline \#10 (D5) & & & D5 & $20 \times 40$ & 800 \\
\hline$\# 11$ (B1) & \multirow{5}{*}{ B } & \multirow{5}{*}{$\begin{array}{l}\text { Busan, } \\
\text { southern part } \\
\quad\left(35.06^{\circ}\right)\end{array}$} & B1 & $40 \times 40$ & 1.600 \\
\hline$\# 12$ (B2) & & & B2 & $80 \times 20$ & 1.600 \\
\hline$\# 13$ (B3) & & & B3 & $20 \times 80$ & 1.600 \\
\hline$\# 14$ (B4) & & & B4 & $40 \times 20$ & 800 \\
\hline \#15 (B5) & & & B5 & $20 \times 40$ & 800 \\
\hline
\end{tabular}

\section{Results and discussion}

\subsection{Sensitivity analysis in terms of the unit panel}

This study analyzed the relationship between the AEG/unit and the ILP in terms of the unit panel by considering the change of the SoP. The relationship between the AEG/unit and the ILP depends on the following three impact factors: (i) the meridian altitude at noon of the winter solstice (refer to SI Table S4); (ii) the SoP; and (iii) the ToP (refer to SI Table S8).

SI Figure S5 shows the AEG/unit and the ILP based on the SoP. First, the results of the AEG/unit are as follows: (i) when the SoP was from $0^{\circ}$ to $35^{\circ}$, the AEG/unit tended to increase; but (ii) when the SoP was from $35^{\circ}$ to $90^{\circ}$, the AEG/unit tended to decrease. Next, the results of the ILP are as follows: (i) when the SoP was from $0^{\circ}$ to $60^{\circ}$, the ILP tended to increase; and (ii) when the SoP was from $60^{\circ}$ to $90^{\circ}$, the ILP tended to decrease.

The reasons for such trends can be determined from the geographical factors (i.e., the latitude and the monthly meridian altitude) (refer to SI Table S4). The target building in model application is located in Seoul, the latitude of which is $37.30^{\circ} \mathrm{N}$, and the monthly meridian altitude of which is between $29.20^{\circ}$ (at noon of the winter solstice, $29.20^{\circ}=90^{\circ}-$ $37.30^{\circ}-23.5^{\circ}$ ) and $76.20^{\circ}$ (at noon of the summer solstice, $76.20^{\circ}=90^{\circ}-37.30^{\circ}+23.5^{\circ}$ ). Therefore, the analysis results are as follows: (i) when the SoP became perpendicular to the average of the monthly meridian altitude $\left(52.70^{\circ}\right)$ - namely, when SoP was near $37.30^{\circ}$ (i.e., $35^{\circ}$ ) - the AEG/unit peaked (at $262.19 \mathrm{kWh} / \mathrm{EA}$ ) (refer to the red circle in SI Figure S5); and (ii) when the SoP became perpendicular to the meridian altitude at noon of the winter 
solstice $\left(29.20^{\circ}\right)$ - namely, when the SoP was near $60.80^{\circ}$ (i.e., $60^{\circ}$ ) - the ILP was analyzed to have peaked $(2.009 \mathrm{~m}$ ) (refer to the blue circle in SI Figure S5).

Figure 3 shows the analysis results, which were generally divided into three zones. It was determined that the SoP between Zone (A) and Zone (B) was the same as the latitude in the target region $\left(37.30^{\circ}\right.$ in the case of Seoul), and that the SoP between Zone (B) and Zone (C) was the same as the latitude $+23.5\left(60.80^{\circ}\right.$ in the case of Seoul). The analysis results at each zone are as follows: (i) in Zone (A) (from $0^{\circ}$ to $35^{\circ}$ ), as the Sop increased, both the AEG/ unit and the ILP increased (refer to Zone (A) in SI Figure S5); (ii) in Zone (B) (from $35^{\circ}$ to $60^{\circ}$ ), as the SoP increased, the AEG/unit decreased and the ILP increased (refer to Zone (B) in SI Figure S5); and (iii) in Zone (C) (from $60^{\circ}$ to $90^{\circ}$ ), as the SoP increased, both the AEG/unit and the ILP decreased (refer to Zone (C) in SI Figure S5).

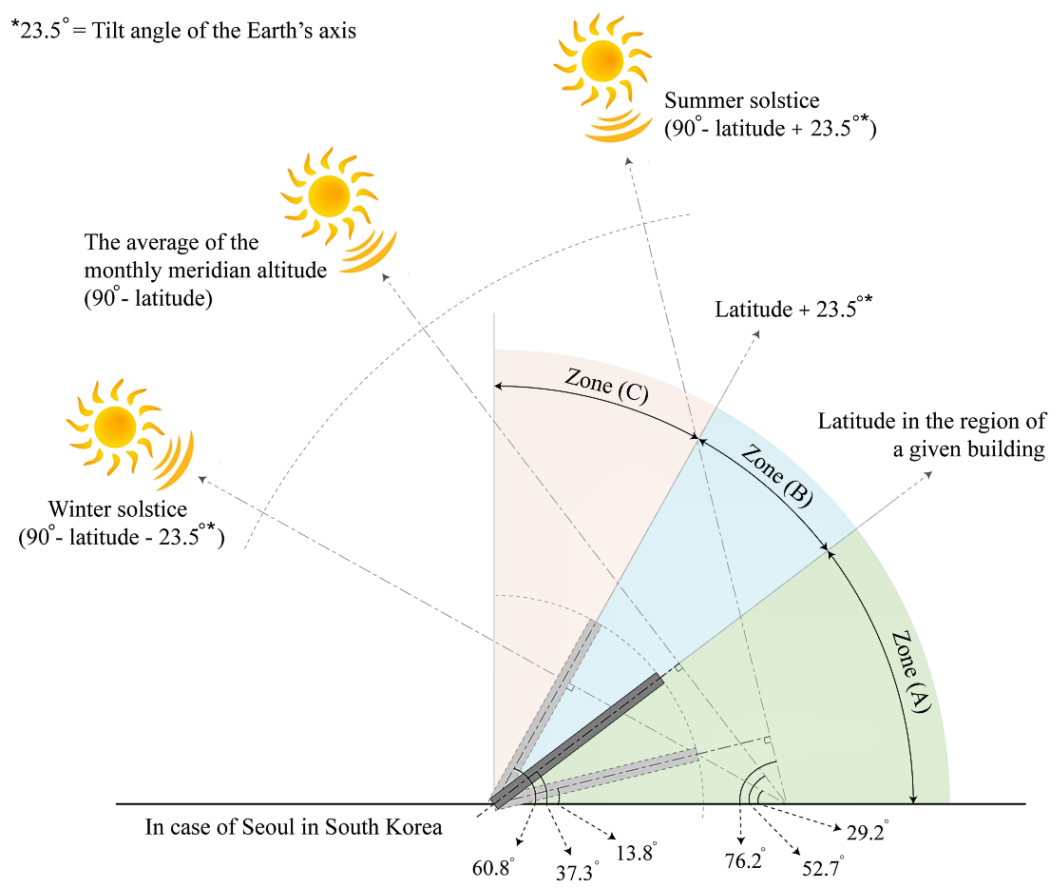

Fig. 3. Three zones according to the slope of the installed panel (SoP)

\subsection{Sensitivity analysis in terms of the rooftop PV system}

According to the sensitivity analysis in terms of the unit panel, it was determined that the relationship between the AEG/unit and the ILP was most influenced by the SoP. Since this relationship in terms of the unit panel can finally affect the life-cycle economic and environmental performance of the rooftop PV system, this study examined the complex relationships among the several impact factors in terms of the rooftop PV system. Based on the three zones (i.e., Zone (A), Zone (B), and Zone (C)) as shown in Figure 3, the sensitivity analysis in terms of the rooftop PV system was conducted (the detailed analysis results of which are shown in SI Table S9). 
- Correlation between the ILP and the NoP: The ILP depends on the meridian altitude at noon of the winter solstice, the SoP, and the ToP (refer to SI Figure S3), which can affect the NoP to be installed on the rooftop area of the target building. As shown in SI Figure S6, in all the zones (i.e., Zones (A), (B), and (C)), the ILP and the NoP were negatively correlated. Such a trend changed when the SoP was $60^{\circ}$.

- Correlation between the NoP and the IIC: The IIC of the rooftop PV system depends on the NoP. As shown in SI Figure S7, the NoP and the IIC were positively correlated in all the zones (i.e., Zones (A), (B), and (C)).

- Correlation between the NoP and the total AEG: The total AEG of the rooftop PV system depends on the NoP. As shown in SI Figure S8, in Zones (A) and (B), the NoP and the total AEG were positively correlated. However, in Zone (C), they were negatively correlated. This is because as the SoP increases, the AEG/unit rapidly decreases (refer to Zone (C) in SI Figure S5). In conclusion, as the SoP increases, the NoP increases. However, the total AEG decreases.

- Correlation between the NoP and the NPV: The NPV of the rooftop PV system depends on the NoP. As shown in SI Figure S9, in Zones (A) and (B), the NoP and the NPV were positively correlated, whereas in Zone $(\mathrm{C})$, they were markedly negatively correlated. This was because as the SoP increased, the IIC increased (refer to Zone (C) in SI Figure S7) but the total AEG decreased (refer to Zone (C) in SI Figure S8).

- Correlation between the NoP and the SIR: The SIR of the rooftop PV system depends on the AEG/unit. As shown in SI Figure S10, in all the zones (i.e., Zones (A), (B), and $(\mathrm{C})$ ), the AEG/unit and the SIR were positively correlated. Such a trend changed when the SoP was $35^{\circ}$.

- Correlation between the SIR and the NPV under the budget limit: To evaluate the lifecycle economic and environmental performance of the rooftop PV system, the NPV and the SIR should be analyzed at the same time. First, as the SoP increased, the NPV tended to decrease in all the zones (refer to SI Figure S9). Next, as the SoP increased, the SIR increased in Zone (A) and decreased in Zones (B) and (C) (refer to SI Figure S10). As a result, as shown in Figure 4, it was determined that there was a trade-off relationship between the NPV and the SIR in Zone (A). Thus, based on the project goal of the final decision-maker - namely, based either on the absolute or relative value (i.e., NPV or SIR) - the optimal solution can be determined. Meanwhile, the optimal solution should be selected within the budget limit of the target project. If the budget limit is US $\$ 125,000$, the optimal solution should be determined when the SoP is between $15^{\circ}$ and $35^{\circ}$. Under this background, this study aimed to develop the life-cycle economic and environmental assessment model for establishing the optimal implementation strategy of the rooftop PV system.

\subsection{Optimization results for model application}

SI Table S10 shows the top 10 optimization results in the first scenario (scenario \#1 in Table 2) (i.e., region: Seoul; rooftop shape: $40 \mathrm{~m} \times 40 \mathrm{~m}$; and rooftop area: 1,600 $\mathrm{m}^{2}$ ). First, it was determined that the $\mathrm{SIR}_{25}$ of the optimal solution was at $2.266(226.6 \%)$ when the 


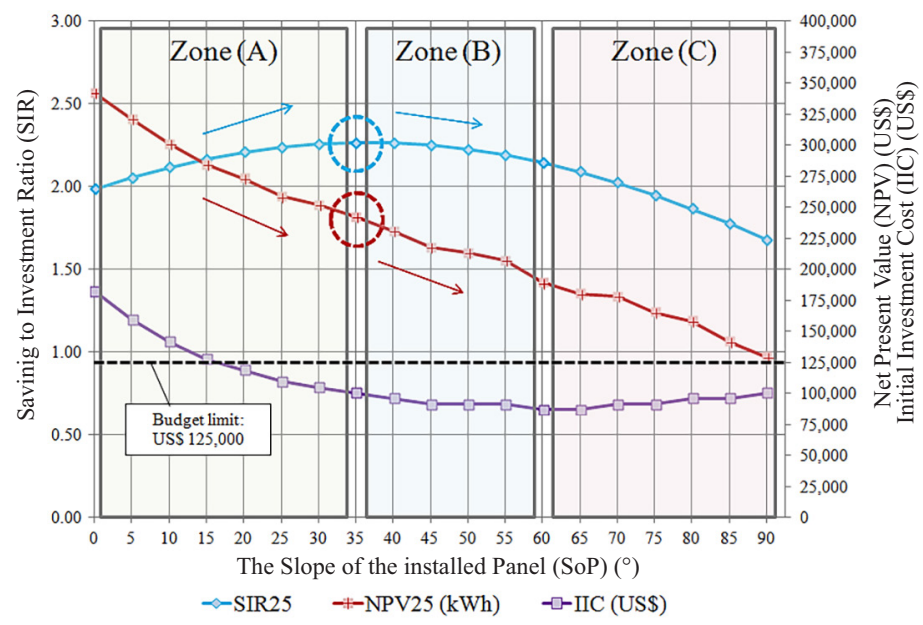

Fig. 4. The correlation between the SIR and the NPV under the maximum budget limit

ToP is Product 30 (HIS-S218SF) (refer to SI Table S7) and the SoP is $36^{\circ}$. From the second to the tenth optimal solutions, the SoP was determined based on the ToP. And then, the other optimization parameters (such as the NoP_W, the NoP_L, and NoP) and the optimization results (such as the AEG/unit, the total AEG, the IIC, the NPV, and the SIR) were determined based on the SoP.

Table 3 shows the optimization results by scenario established based on the regional climate factors and building characteristics. First, in terms of the regional climate factors, the optimization results (i.e., scenarios \#1, \#6, and \#11 in Table 3) were generated by considering the latitude, the monthly meridian altitude, the MADSR, and the monthly average temperature. Second, in terms of the building characteristics, the optimization results were generated by considering the rooftop shape and the rooftop area. Namely, when $\mathrm{SIR}_{25}$ was set as the optimization goal, it was determined to be at 2.266 (226\%), 2.485 (248\%), and 2.540 (254\%) for Seoul (northern part), Daejeon (central part), and Busan (southern parte), respectively.

Meanwhile, to evaluate the robustness and reliability of the developed model, this study has established the following two criteria.

- For the consideration of the effectiveness of the optimal solution: It was determined that the developed model can generate the optimal solution by comprehensively considering various impact factors such as the optimization goal, regional factors, AoP, SoP, ToP, rooftop factors, and budget limit (which can affect the life-cycle economic and environmental performance of the rooftop PV system). For example, if assumed that the final decision-makers consider the SoP $\left(0^{\circ} \sim 90^{\circ}\right)$ and the ToP (Nos. 1 to 49 ) (refer to SI Table S7), which are defined as the adjustable parameters in this study, the optimal solution can be determined from a total of $4,459(=91 \times 49)$ possible scenarios through the optimization process using the GA. 


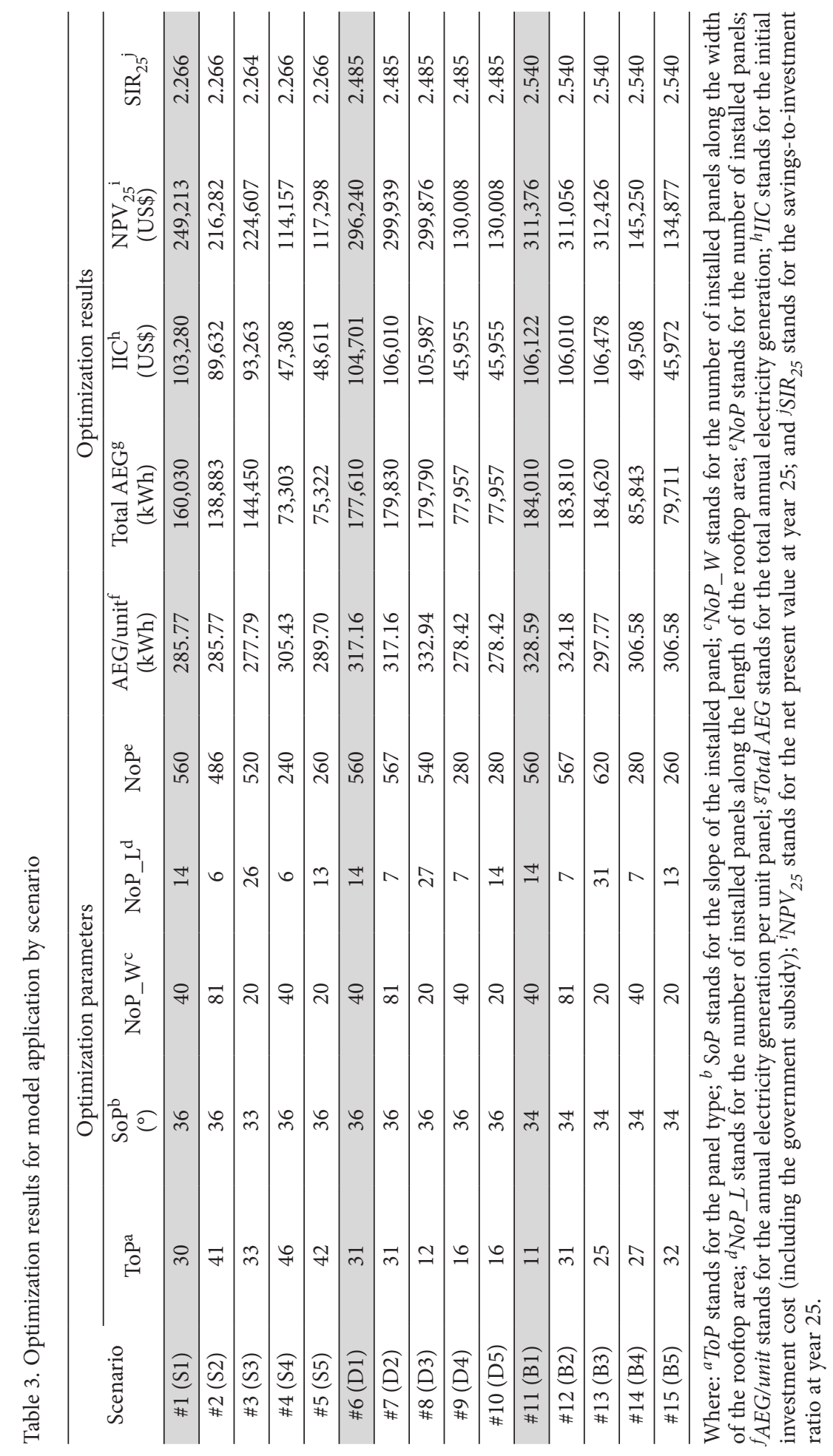


- For coming up with an efficient computation time: It was determined that the time required for determining the optimal solution on a computer (Processor, Intel ${ }^{\varpi} \mathrm{Core}^{\mathrm{Tm}}$ i7-2600 CPU@ 3.40 GHz; RAM, 3.48 GB available) was only 27 seconds. This is because the regional climate factors such as the geographical factors and the meteorological factors can be automatically retrieved from the data-base once the final decision-makers select one of the 16 administrative divisions in South Korea. In addition, it is because the optimization process is applied to the develop model for establishing the optimal implementation strategy of the rooftop PV system.

\section{Conclusions}

To improve the energy performance of existing buildings, the rooftop PV system has great potential among the various types of new renewable energies. This study aimed to develop the life-cycle economic and environmental assessment model for establishing the optimal implementation strategy of the rooftop PV system. This study was conducted in three steps: (i) step 1: definition of the impact factors of the rooftop PV system; (ii) step 2: sensitivity analysis on the impact factors of the rooftop PV system; and (iii) step 3: development of the life-cycle economic and environmental assessment model. The results of this study can be summarized as follows.

- First, based on the geographical factors among the regional factors (i.e., the latitude and the monthly meridian altitude), the range of the SoP was divided into three zones (i.e., Zone (A), Zone (B), and Zone (C)). It was determined that the SoP between Zone (A) and Zone (B) was the same as the latitude in the region of the given building $\left(37.30^{\circ}\right.$ in the case of Seoul), and the SoP between Zone (B) and Zone (C) was the same as latitude $+23.5\left(60.80^{\circ}\right.$ in the case of Seoul).

- Second, the NoP depends on the ToP and the SoP, which resulted in the different IIC and total AEG, and ultimately, the different NPV and SIR. Such analysis results showed a different tendency at each zone. Especially, it was determined that there was a trade-off relationship between the NPV and the SIR in Zone (A). Thus, based on the project goal of the final decision-maker - namely, based either on the absolute or relative value (i.e., NPV or SIR) - the optimal solution can be determined.

- Third, the robustness and reliability of the developed model were evaluated in terms of two perspectives: (i) in terms of the effectiveness, it was analyzed that the optimal solution can be generated by considering the various factors of the rooftop PV system. As a result, when $\mathrm{SIR}_{25}$ was set as the optimization goal, it was determined to be at 2.540, 2.485, and 2.266 for Busan (southern part of South Korea), Daejeon (central part of South Korea), and Seoul (northern part of South Korea), respectively; and (ii) in terms of the efficiency, it was concluded that the time required for determining the optimal solution was only 27 seconds.

The developed model can be used by final decision makers such as policymakers, construction managers, contractors in a variety of perspectives as follows.

- The developed model could be used for policymakers to analyze the return on investment of the rooftop PV system from the life cycle perspective, and finally to establish the appropriate level of the government subsidy. 
- The developed model could enable architects and construction managers to assess the life-cycle economic and environmental performance of the rooftop PV system in the early design phase by considering the energy demand of a given building.

- The developed model could enable contractors to analyze the economic value of the rooftop PV system in a competitive bidding process.

- As the optimization model was developed using Microsoft Excel's VBA, the final decision-makers (such as policymakers, construction managers, and contractors) could assess the life-cycle economic and environmental performance of the rooftop PV system simply by entering the optimization parameters.

- The developed model could be applied to any other new renewable energy system and be extended to any other country or sector in the global environment.

Meanwhile, this study has the following limitations: (i) There are several types of optimization goals (e.g., NPV as an absolute index, SIR as a relative index, etc.) which should be considered simultaneously to achieve the success of PV projects. However, this study has defined the SIR as the fitness function (i.e., the optimization goal). Since it was determined that there was a trade-off relationship between the NPV and the SIR, multiobjective optimization process should be introduced to address this challenge; and (ii) The mandatory renewable energy installation program should be taken into account from the political perspective. In South Korea, the public building should introduce any types of renewable energy systems to supply over $20 \%$ of energy consumptions in the operation and maintenance phase by 2020 .

To solve the above-mentioned limitations, the research team has currently conducted the follow-up studies: (i) to develop an integrated multi-objective optimization model for determining the optimal solution in the rooftop PV system, focusing on the profitability; and (ii) to develop the decision support model for establishing the optimal energy retrofit strategy from the political perspective which can achieve the national carbon emission reduction target or the mandatory renewable energy installation program.

\section{Acknowledgements}

This work was supported by the National Research Foundation of Korea (NRF) grant funded by the Korea government (MSIP; Ministry of Science, ICT \& Future Planning) (No. NRF-2015R1A2A1A05001657).

\section{References}

Badescu, V. 2006. Simple optimization procedure for silicon-based solar cell interconnection in a seriesparallel PV module, Energy Conversion and Management 47(9-10): 1146-1158. http://dx.doi.org/10.1016/j.enconman.2005.06.018

Bank of Korea Economic Statistics System (ECOS) [online]. 2013 [cited 7 May 2013]. Available from Internet: http://ecos.bok.or.kr

Bhatti, M. A. 2000. Practical optimization methods. New York: Springer-Verlag. 
Bojić, M.; Bigot, D.; Miranville, F.; Parvedy-Patou, A.; Radulovic, J. 2012. Optimizing performance of photovoltaics in Reunion Island-tilt angle, Progress in Photovoltaics: Research and Applications 20(8): 923-935. http://dx.doi.org/10.1002/pip.1159

Braun, A.; Katz, E. A.; Gordon, J. M. 2013. Basic aspects of the temperature coefficients of concentrator solar cell performance parameters, Progress in Photovoltaics: Research and Applications 21(5): 1087-1094. http://dx.doi.org/10.1002/pip.2210

Brearley, D. 2009. C-Si photovoltaic trends: design, purchasing and 2009 specs, Solar Pro Magazine 2009 June/July, 49-74.

Construction Association of Korea (CAK). 2012. Monthly construction market price (October). Seoul, South Korea, CAK.

Dell'Isola, A. J.; Kirk, S. J. 2003. Life cycle costing for facilities. Kingston, United States: Reed Construction Data.

Department of State (DOS). 2010. U.S. climate action report 2010: Fifth national communication of the United States of America under the United Nations Framework Convention on Climate Change. DOS, Washington, DC.

Dincer, F.; Meral, M. E. 2010. Critical factors that affecting efficiency of solar cells, Smart Grid and Renewable Energy 1: 47-50.

European Environment Agency (EEA). 2011. Greenhouse gas emission trends and projections in Europe 2011: tracking progress towards Kyoto and 2020 targets. EEA, Copenhagen.

Gen, M.; Cheng, R. 2000. Genetic algorithms \& engineering optimization. New York: Wiley-Interscience.

Gong, X.; KulKarni, M. 2005. Design optimization of a large scale rooftop photovoltaic system, Solar Energy 78(3): 362-374. http://dx.doi.org/10.1016/j.solener.2004.08.008

Harder, E.; Gibson, J. M. 2011. The costs and benefits of large-scale solar photovoltaic power production in Abu Dhabi: United Arab Emirates, Renewable Energy 36(2): 789-796. http://dx.doi.org/10.1016/j.renene.2010.08.006

Hoffmann, S.; Koehl, M. 2014. Effect of humidity and temperature on the potential-induced degradation, Progress in Photovoltaics: Research and Applications 22(2): 173-179. http://dx.doi.org/10.1002/pip.2238

Hong, T.; Koo, C.; Kwak, T. 2013. Framework for the implementation of a new renewable energy system in an educational facility, Applied Energy 103(3): 539-551.

http://dx.doi.org/10.1016/j.apenergy.2012.10.013

Hong, T.; Koo, C.; Lee, S. 2014a. Benchmarks as a tool for free allocation through comparison with similar projects: focused on multi-family housing complex, Applied Energy 114(2): 663-675. http://dx.doi.org/10.1016/j.apenergy.2013.10.035

Hong, T.; Koo, C.; Kwak, T.; Park, H. 2014b. An economic and environmental assessment for selecting the optimum new renewable energy system for educational facility, Renewable and Sustainable Energy Reviews 29(1): 286-300. http://dx.doi.org/10.1016/j.rser.2013.08.061

Hong, T.; Koo, C.; Park, J.; Park, H. S. 2014c. A GIS (geographic information system)-based optimization model for estimating the electricity generation in the rooftop PV (photovoltaic) system, Energy 65: 190-199. http://dx.doi.org/10.1016/j.energy.2013.11.082

Intergovernmental Panel on Climate Change (IPCC). 2007. Climate Change 2007: Synthesis report. IPCC.

International Energy Agency (IEA). 2008a. Community-scale solar photovoltaics: housing and public development example. IEA.

International Energy Agency (IEA). 2008b. Urban BIPV in the new residential construction industry 2008. IEA.

International Energy Agency (IEA). 2010. World Energy Outlook 2010. IEA. 
International Renewable Energy Agency (IRENA). 2012. Renewable energy technologies: cost analysis series, volume 1: power sector, issue 4/5 solar photovoltaics. IRENA, Abu Dhabi.

Joint Research Centre (JRC). 2011. PV status report 2011. JRC, Italy.

Kaldellis, J.; Zafirakis, D. 2012. Experimental investigation of the optimum photovoltaic panels' tilt angle during the summer period, Energy 38(1): 305-314. http://dx.doi.org/10.1016/j.energy.2011.11.058

Koo, C.; Hong, T.; Lee, M.; Park, H. S. 2013. Estimation of the monthly average daily solar radiation using geographical information system and advanced case-based reasoning, Environmental Science \& Technology 47: 4829-4839. http://dx.doi.org/10.1021/es303774a

Koo, C.; Hong, T.; Park, H. S.; Yun, G. 2014. Framework for the analysis of the potential of the rooftop photovoltaic system to achieve the net zero-energy solar buildings, Progress in Photovoltaics: Research and Applications 22(4): 462-478. http://dx.doi.org/10.1002/pip.2448

Korea Electric Association (KEA). 2000. Replacement fossil fuel by solar energy. KEA, Seoul, South Korea.

Korea Energy Management Corporation (KEMCO). 2013a. Registration and trade system for Korea voluntary emission reduction project [online]. KEMCO, Seoul, South Korea [cited 7 May 2013]. Available from Internet: https://kver.kemco.or.kr

Korea Energy Management Corporation (KEMCO). 2013b. Introduction to the 1 million green home project [online]. KEMCO, Seoul, South Korea [cited 7 May 2013]. Available from Internet: http:// greenhome.kemco.or.kr

Korea Mech. Const. Contractors Association (KMCCA). 2011. Exploration of new regeneration energy. KMCCA, Seoul, South Korea.

Korean Statistical Information Service (KOSIS) [online]. 2013 [cited 7 May 2013]. Available from Internet: http://kosis.kr

Lee, M.; Koo, C.; Hong, T.; Park, H. S. 2014. Framework for the mapping of the monthly average daily solar radiation using an advanced case-based reasoning and a geostatistical technique, Environmental Science and Technology 48: 4604-4612. http://dx.doi.org/10.1021/es405293u

Levinson, R.; Akbari, H.; Pomerantz, M.; Gupta, S. 2009. Solar access of residential rooftops in four California cities, Solar Energy 83: 2120-2135. http://dx.doi.org/10.1016/j.solener.2009.07.016

Melbourne Energy Institute (MEI). 2011. Renewable energy technology cost review. MEI, Melbourne.

Minister of Natural Resources (MNR). 2010. Clean energy project analysis: RETScreen engineering \& cases textbook. 3rd ed. MNR, Canada.

Ministry of Knowledge Economy (MKE). 2011. Composition of expanding through the research of solar power supply potential. MKE, Korea.

New and Renewable Energy Centre (NREC). 2013. Subsidies for general dissemination [online], [cited 7 May 2013]. Available from Internet: http://www.energy.or.kr/knrec/12/KNREC120200.asp

Ordonez, J.; Jadraque, E.; Alegre, J.; Martinez, G. 2010. Analysis of the photovoltaic solar energy capacity of residential rooftops in Andalusia, Renewable and Sustainable Energy Reviews 14(7): 21222130. http://dx.doi.org/10.1016/j.rser.2010.01.001

Sarhaddi, F.; Farahat, S.; Ajam, H.; Behzadmehr, A. 2009. Exergetic optimization of a solar photovoltaic array, Journal of Thermodynamics. Article number 313561. http://dx.doi.org/10.1155/2009/313561

Siraki, A. G.; Pillay, P. 2012. Study of optimum tilt angles for solar panels in different latitudes for urban applications, Solar Energy 86: 1920-1928. http://dx.doi.org/10.1016/j.solener.2012.02.030

Tiris, M.; Tiris, C. 1998. Optimum collector slope and model evaluation: case study for Gebze, Turkey, Energy Conversion and Management 39(3-4): 167-172.

http://dx.doi.org/10.1016/S0196-8904(96)00229-4 
United Nations (UN). 1998. Kyoto Protocol to the United Nations Framework Convention on Climate Change. UN.

Weinstock, D.; Appelbaum, J. 2009. Optimization of solar photovoltaic fields, Journal of Solar Energy Engineering 131(3): 1-9. http://dx.doi.org/10.1115/1.3142705

World Energy Council (WEC). 2010. 2010 Survey of energy resources. WEC, U.K.

Zhao, Q.; Wang, P.; Goel, L. 2010. Optimal PV panel tilt angle based on solar radiation prediction, in IEEE 11th International Conference Probabilistic Methods Applied to Power Systems (PMAPS), 14-17 June 2010, Singapoure. http://dx.doi.org/10.1109/PMAPS.2010.5528960

Choongwan KOO is a research professor in the Department of Architectural Engineering at Yonsei University and a visiting scholar in the Division of Construction Engineering and Management at Purdue University. His primary research areas include sustainable construction management system, building energy efficiency, new and renewable energy, solar photovoltaics, carbon emissions reduction, geographic information system, decision support system, data-mining technique, case-based reasoning, life cycle cost, life cycle assessment, multi-objective optimization for time-cost trade-off, and cost optimization.

Taehoon HONG is an associate professor in the Department of Architectural Engineering at Yonsei University. He is an associate editor in the Journal of Management in Engineering, ASCE. His main research areas include sustainable construction management system, building energy efficiency, solar photovoltaics, life cycle cost analysis, life cycle assessment, construction productivity, infrastructure management, facility management, and construction project cost control.

Joonho PARK is an analyst in the Department of Industrial \& Logistics at CBRE Korea. His primary research areas include real estate valuation, sustainable construction management, life cycle cost, life cycle assessment, educational facility, geographical information system, and solar photovoltaic. 